\title{
NATION-STATES CRISIS, AUSTERITY AND CITIES TRANSFORMATION IN EUROPE
}

ANDRÉ CARMO $^{1}$

Decorreu no dia 20 de Fevereiro de 2014, no Auditório do Instituto de Investigação Interdisciplinar da Universidade de Lisboa, o seminário internacional Nation-states crisis, austerity and cities transformation in Europe. Organizado por Teresa Barata Salgueiro, Isabel André, Mário Vale e Jorge Malheiros, investigadores pertencentes ao ZOE - Dinâmicas e Políticas Regionais e Urbanas, o mais recente núcleo de investigação do Centro de Estudos Geográficos da Universidade de Lisboa (CEG-UL), este seminário debruçou-se sobre algumas das mais candentes problemáticas da atualidade, nomeadamente, a crise e a austeridade, a partir de uma perspetiva regional e urbana. Em boa hora o fizeram, na medida em que o contributo da comunidade geográfica portuguesa para a compreensão da crise e das suas reverberações sócio-espaciais tem sido, efetivamente, escasso e pouco consistente, tendo esta iniciativa prestado um contributo importante para a inversão desse panorama.

Na sessão de abertura, Diogo Abreu e Maria Lucinda Fonseca, respetivamente diretor do CEG-UL e diretora do Instituto de Geografia e Ordenamento do Território da Universidade de Lisboa (IGOT-UL), sublinharam a necessidade de compreender melhor os contornos da crise numa ótica geográfica, colocando a cidade no centro do debate, não apenas enquanto escala de análise privilegiada, mas também enquanto espaço social, no qual os impactos da crise se têm revelado particularmente contundentes e nefastos.

Mário Vale, na sua intervenção inicial, procurou delinear as fronteiras da discussão ulteriormente ocorrida, colocando em evidência a aparente (ir)relevância do território no atual debate político e académico sobre as causas e os impactos da crise, designadamente a incapacidade para compreender o modo diversificado e assimétrico como estes se fazem sentir. Por outro lado, sublinhou a pertinência de produzir conhecimento a partir do contexto específico das cidades e regiões do sul da Europa, estudando as suas especificidades e contrastes relativamente a outros contextos geográficos. Apresentou ainda uma grelha de leitura dos comportamentos de diferentes territórios face à crise, considerando as variações temporais e a cumulatividade dos impactos, chamando no entanto a atenção para a escassez de informação adequada para produzir análises qualificadas.

1 Investigador do Centro de Estudos Geográficos da Universidade de Lisboa.

E-mail: carmo@campus.ul.pt 
A primeira mesa redonda - The neoliberal development processes of cities and regions - contou com duas intervenções. Na primeira, intitulada Governing the austerity state: the politics of local and regional development in England, Andy Pike (CURDS, Newcastle) explorou a reconfiguração atualmente em curso do Estado britânico, designadamente a emergência daquilo que designou Estado austeritário. Em seu entender, numa leitura que acompanhamos, este processo não visa oferecer respostas à crise mas, pelo contrário, representa um projeto político deliberado conduzido pela direita, que encontra hoje condições privilegiadas para o levar a cabo. Entre outras mudanças, assiste-se à passagem de uma lógica centrada nas pessoas para uma outra que gravita em torno dos mercados, de eleições periódicas para avaliações regulares, dos cidadãos para os investidores, da opinião pública para as taxas de juro, dos serviços públicos para o serviço da dívida. Em nome do crescimento local, do primado do localismo e da necessidade de se passar do Big Government para a Big Society, o atual governo de coligação liberal-conservador no Reino Unido tem levado a cabo este processo com determinação.

Por seu turno, Philip O'Connell (University College Dublin), com The Impact of the Great Recession on the Irish Labour Market, traçou um retrato detalhado do modo como a crise tem influenciado o mercado de trabalho irlandês. Em seu entender, a crise é um fenómeno multifacetado que, no contexto irlandês, deve levar em linha de conta cinco aspetos, nomeadamente, uma grande bolha imobiliária, o colapso do sistema bancário, uma recessão severa, a crise fiscal do Estado e um desemprego massivo. Entre as tendências descritas pelo autor, encontram-se a aposta numa política de redução de custos do trabalho, uma diminuição da conflitualidade social de 2010 em diante e a passagem do Estado-providência para um Estado-assistencialista que, no entanto, penaliza desproporcionadamente a população irlandesa de menores rendimentos.

A segunda mesa redonda - Crisis and austerity inflaming tensions and conflicts in the urban space - incluiu três apresentações. A primeira, Tracing gendered aspects of the Greek crisis in Athens, da autoria de Dina Vaiou (National Technical University of Athens), partiu de uma narrativa crítica da crise, salientando as dificuldades analíticas decorrentes da grande velocidade a que ocorrem as transformações, e comparou o modo como a crise é sentida diferenciadamente por homens e mulheres. A partir de uma abordagem etnográfica, a autora procurou revelar as pessoas que se escondem por trás das estatísticas económicas, prestando atenção às suas práticas quotidianas e ao modo como lidam com a crise. A sua análise evidenciou três impactos negativos da crise na sociedade grega contemporânea, nomeadamente, o crescente número de trabalhadores que não conseguem escapar a situações de pobreza, o desemprego massivo e a alarmante ascensão de movimentos neo-nazis (ex: Aurora Dourada) cada vez mais influentes em termos sociais e políticos. Concomitantemente, o medo e a insegurança nos diferentes espaços da vida quotidiana parecem também ganhar terreno.

Adotando um registo mais ensaístico, João Seixas (ICS-UL), em The reproduction of the crisis and the pressures of the urban spaces, procurou lançar alguma luz sobre as transformações em curso no contexto da Área Metropolitana de Lisboa. Começou por esboçar uma periodiziação da crise - 2008 a 2010 e 2010 até hoje - a partir dos contrastes encontrados num conjunto vasto de indicadores (ex: (des)emprego, utilização de transportes públicos, migrações). Seguidamente colocou o enfoque sobre a política urbana, a diferentes escalas, sublinhando a inexistência de uma estratégia político-urbana clara (sobretudo às escalas da cidade e do bairro), os baixos níveis de envolvimento e de participação social e política dos cidadãos portugueses, o aparecimento de movimentos urbanos alternativos (ex: HABITA, Plataforma Gueto, Observatório das transformações aceleradas na cidade de Lisboa) e um 
conjunto diversificado (e nalguns aspetos contraditório) de propostas anti-crise concebidas pela autarquia lisboeta (ex: reestruturação político-administrativa, regeneração urbana, apoio ao empreendedorismo urbano).

Frank Eckardt (Bauhaus-Universität Weimar), numa comunicação intitulada Urban austerity in Germany: financial crisis in a prospering country, transporta-nos para a experiência alemã da crise. Começando por tecer algumas considerações relativamente à arquitetura financeira das cidades germânicas, o autor abordou depois alguns dos problemas decorrentes da austeridade (ex: encerramento de equipamentos coletivos locais e degradação de infra-estruturas). Seguidamente, colocou o enfoque sobre alguns dos fatores estruturais da crise orçamental, designadamente, a descida do investimento de 1970 em diante, acompanhada do aumento dos custos sociais, o processo de desindustrialização, cujos impactos estão ainda por determinar em toda a sua extensão e profundidade, e o papel central ocupado pela cultura política social democrata em todo este processo. Terminou, apresentando quatro casos de estudo (Bremerhaven, Hagen, Offenbach e Ludwigshafen), que adotaram estratégias urbanas distintas para enfrentar a crise.

A terceira mesa redonda - Needed and desired responses for cities of tomorrow - contou com duas comunicações. Costis Hadjimichalis (Harokopio University) apresentou Crisis and the need for a paradigm shift in urban and regional development, partindo do pressuposto que a crise atual é uma crise de desenvolvimento desigual e não uma especificidade europeia. Segundo este autor, as principais correntes teóricas que procuram explicar a crise (ex: nova geografia económica, economia institucionalista) revelam-se incapazes de o fazer de modo adequado, pois enquadram o problema de uma maneira despolitizada, inteiramente compatível com a perspetiva neoliberal. Entre os aspetos particularmente problemáticos que são partilhados pelas teorias de desenvolvimento urbano/regional baseadas nessas correntes, contam-se a apologia do mercado, competitividade, empreendedorismo e flexibilidade, as privatizações, a passagem da governação para a governança, o planeamento através de projetos, um enfoque nas cidades mais importantes que negligencia os lugares indiferenciados, e alguma desatenção relativamente ao papel desempenhado pelo capital financeiro e pelo mercado fundiário. Em alternativa, o autor defende a necessidade de uma mudança de paradigma que, simultaneamente, revisite o legado da economia política e integre as lições provenientes dos atuais movimentos sociais emancipatórios. Efetivamente, conclui, é preciso regressar às perguntas simples: quem perde e quem beneficia com a crise atual, como e porquê?

Por fim, em A disintegrated capitalism: the territorial links of a reactionary political economy, José Reis (CES-Coimbra) começou por refletir acerca da existência de um capitalismo inclusivo, tentando perceber quais as suas características definidoras, afirmando que essa configuração foi radicalmente alterada pela austeridade, concebida enquanto política económica reacionária que visa, essencialmente, diminuir os rendimentos do trabalho e minimizar o papel do Estado-providência na economia. Tendências como a enorme transferência de riqueza do trabalho para o capital e a abrupta reestruturação do Estado, revelam-se, deste ponto de vista, paradigmáticas. A partir de uma abordagem institucionalista que concebe o território enquanto elemento constitutivo do enquadramento institucional, o autor propõe, entre outras alternativas, a afirmação de formas de competitividade orientadas para a economia interna e a redução dos custos unitários do trabalho como objetivos primordiais.

Em jeito de balanço, gostaríamos de salientar a pertinência deste seminário que, indo claramente para além da mera discussão académica, representou, em si mesmo, um primeiro passo, que deve ter continuidade, no desenvolvimento de uma intervenção pública geografi- 
camente qualificada e informada. Por outro lado, sublinha-se também a grande riqueza trazida pela pluralidade disciplinar, epistemológica e metodológica dos diferentes intervenientes. A crise é um fenómeno altamente complexo e dinâmico que dificilmente pode ser compreendido se não for examinado a partir de diferentes posicionamentos. Por fim, num momento em que a universidade portuguesa e o sistema científico nacional sofrem um ataque sem precedentes, que compromete a sua própria existência e viabilidade, saudamos a realização de um encontro desta natureza que, em nossa opinião, mostrou claramente que as ciências sociais desempenham um papel fundamental, não apenas para a compreensão do mundo contemporâneo mas também para a construção de um futuro pós-crise, mais justo e democrático.

O autor deste texto segue o acordo ortográfico de 1990. 